\title{
Effect of clonidine on the release of serotonin from the rat hippocampus as measured by microdialysis
}

\author{
Mitsuhiro Yoshioka", Machiko Matsumoto", Hiroko Togashi", Charles B. Smith" and Hideya Saito"

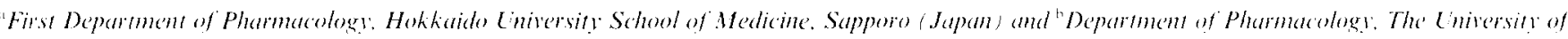 \\ Michigan Medical School. Ann Arhor. MI 48109-0626 (LSA) \\ (Received 21 December 1991: Revised version received 6 February 1992: Acepted 10 February 1992)
}

Ke: ineds: 5-Hydroxytryptamine: $x_{2}$-Adrencrgic receptor: Hippocampus; Heteroreceptor: Microdialysis

\begin{abstract}
The purpese of the present study is 10 clarify the effect of clonidine on the release of serotonin from the rat hippocampus in vivo. For this purpose. endogenous serotonin release wats measured by brain microdialysis. Potassium-evoked serotonin release from the hippocampus of lreely moving rats was significantly inhibited when clonidine $\left(10^{\circ} \mathrm{M}\right)$ was added to the perfusion solution, while the 5-hydroxyindoleacetic acid output remained unchanged. In catecholaminergically denervated rats. clonidine $\left(10^{-5} \mathrm{M}\right)$ also inhibited the potassium-evoked serolonin release from the hippocampus and the 5-hydroxyindoleacetic acid output was unaffected by clonidine. These results suggest that the inhibitory effect of clonidine on serotonin

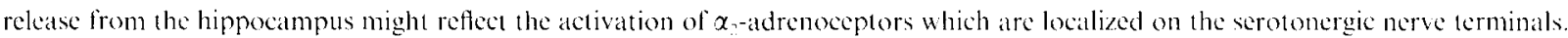

Serotonin (5-HT) and norepinephrine (NE) are major and important neurotransmitters of the hippocampal formation. The rat hippocampus is densely innervated by both serotonergic and norepinephrinergic neurons from the raphe nuclei [9] and the nucleus locus coeruleus [4], respectively. These neuroanatomical and neurochemical studies indicated the possibility that functional interactions might exist between these monoaminergic systems. Thus, the release of serotonin from serotonergic neurons might be modulated by norepinephrinergic neurons in the hippocampus. This possibility is supported by the in vitro data reported by Frankhuyzen and Mulder [1] showing that norepinephrine inhibits the depolarizalion-induced release of $\left[{ }^{3} \mathrm{H}\right] 5-\mathrm{HT}$ from hippocampal slices via the activation of $\alpha$-adrenoceptors. In addition. Maura et al. [8] indicated that these adrenoceptors belong to the $\alpha_{2}$-subtype. This mechanism may play a physiological role in vivo. So far. little is known about the specific effect of $\alpha_{2}$-adrenoceptor agonists on 5-HT release in vivo in the brain of the rat. The present study was undertaken to elucidate $\alpha_{2}$-adrenoceptor-mediated 5-HT release modulation in the hippocampus of freely moving rats using microdialysis. In order to exclude the possibility that the modulation of 5-HT release by $\alpha_{2}$ -

Comespondence: M. Yoshioka. First Department of Pharmacology. Hokkaido University School of Medicine. Kita-15, Nishi-7. Kita-ku, Sapporo 060). Japan. Fax: (81) 11-717-5286. adrenoceptors is an indirect action. c.g.. via short interneurons, we used some rats that were catecholaminergically denervated by 6-hydroxydopamine (6-OHDA).

Rats were anesthetized with ketamine $(100 \mathrm{mg} / \mathrm{kg}$. i.p.). A $3 \mathrm{~mm}$ concentric dialysis probe (EiCOM, Japan) was stereotaxically implanted into the hippocampus (probe tip: rostral-caudal $-5.8 \mathrm{~mm}$. lateral $-4.8 \mathrm{~mm}$, ventral $-7.0 \mathrm{~mm}$, from bregma and dura surface according to Paxinos and Watson. [10]) and secured in place with dental cement. After the rats recovered from surgery, the probe was continuously perfused $(2 \mu \mathrm{l} / \mathrm{min})$ with Ringer solution. Every $20 \mathrm{~min}$, perfusates were collected in iced vials and immediately injected into a high-performance liquid chromatograph (HPLC, P-500, Irika Kogyo, Kyoto, Japan) with an electrochemical detection system (ECD, E-502, Irika) for the measurement of extracellular levels of 5-HT and its major metabolite, 5hydroxyindoleacetic acid (5-HIAA) [7]. Since 5-HT release from the rat hippocampus became constant 220 min after the initiation of perfusion, a high concentration of $\mathrm{KCl}(120 \mathrm{mM})$ was added to the perfusion solution for $40 \mathrm{~min}$ with or without clonidine $\left(10^{5} \mathrm{M}\right.$, Sigma). At the end of the experiment, brain sections were cut and examined to confirm the insertion site of the dialysis tube.

In order to destroy norepinephrinergic neurons, some rats were injected intracerebroventricularly (i.c.v.) with 6-OHDA (200 $\mu$ g. Sigma) $10 \mathrm{~min}$ after the administration of pargyline ( $25 \mathrm{mg} / \mathrm{kg}$, i.p.. Sigma) to prevent the 

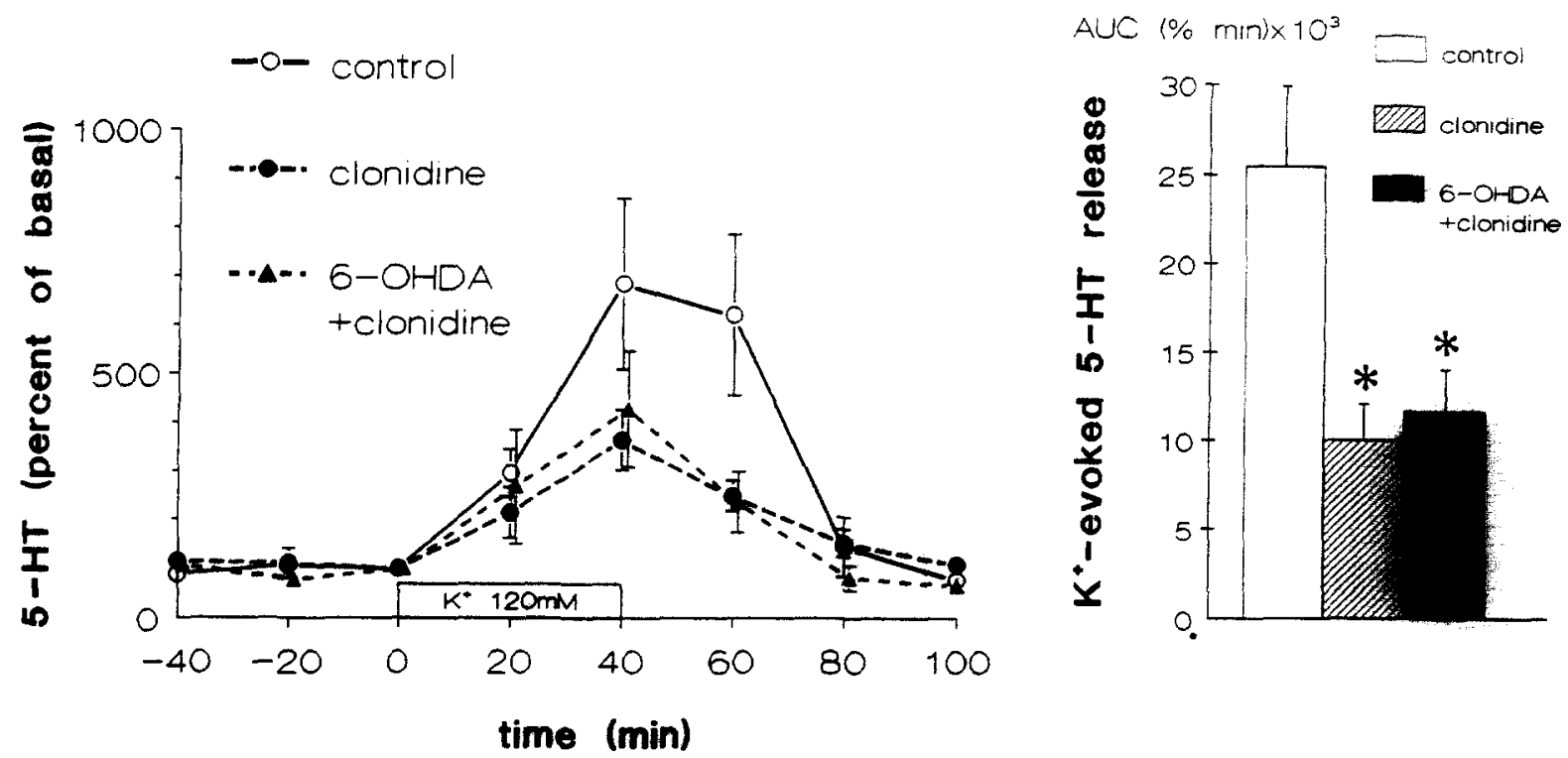

Fig. 1. Effect of clonidine on the potassium-evoked 5-HT release in the hippocampus of freely moving rats. A: $120 \mathrm{mM} \mathrm{KCl}$ was added to the perfusion solution for $40 \mathrm{~min}$ with $(\bullet, n=4)$ or without $(0, n=5)$ clonidine $\left(10^{-5} \mathrm{M}\right)$ in intact rats. $\wedge$ represents 6-OHDA-lesioned rats with clonidine $\left(10^{5} \mathrm{M}, n=5\right)$. Each point represents the mean \pm S.E.M. B: areas under the curves (AUC) were calculated and statistical comparison was made between control and clonidine groups $(* P<0.05)$. Each column represents the mean \pm S.E.M.

destruction of serotonergic neurons. The administration of the neurotoxin was carried out with a microsyringe that was positioned with a stereotaxic apparatus at a depth of $3.3 \mathrm{~mm}$ below the surface of the dura mater. 1.4 $\mathrm{mm}$ lateral to the midline and $0.8 \mathrm{~mm}$ posterior the the bregma. All i.c.v. injections were made in $10 \mu$ volumes and delivered over a period of $2 \mathrm{~min}$. Measurements were taken 14 days after the i.c.v. injection of 6-OHDA. The hippocampal content of NE and 5-HT was determined by HPLC-ECD. The method has previously been described in detail by Matsumoto [6].

The content of 5-HT in the dialysates is expressed as a percentage of the absolute amount of 5-HT contained in the dialysate collected immediately before the addition of $\mathrm{KCl}$. The recovery of each probe was also measured before the experiment to rectify the data.

All results are given as mean \pm S.E.M. Statistical comparisons were carried out using analysis of variance followed by the Student's $t$-test. Values of $P$ less than $5 \%$ were considered significant.

The overal mean basal output of 5-HT in the present study was $27.0 \pm 6.1 \mathrm{fmol} / 40 \mu \mathrm{l}$ and of the major metabolite of 5-HT, 5 -HIAA, was $3.6 \pm 0.6 \mathrm{pmol} / 40 \mu \mathrm{l}$. As shown in Fig. 1 , the addition of $120 \mathrm{mM} \mathrm{KCl}$ produced a maximal $761 \%$ increase in the perfusate of 5-HT as compared with the basal release. On the other hand, 5-HIAA was not affected by potassium-stimulation in spite of the marked increase in 5-HT (Fig. 2). Under these condi- tions, clonidine $\left(10^{5} \mathrm{M}\right)$ added to the perfusion solution significantly decreased the $\mathrm{K}^{+}$-evoked 5-HT release to $363 \%(P<0.05)$, while the 5-HIAA output was unaffected by clonidine. The areas under the curves (AUC) of the 5-HT release in control and clonidine-applied groups were $25.4 \pm 4.41\left(\times 10^{3} \% \cdot \min , n=5\right)$ and $10.0 \pm 2.03\left(\times 10^{3}\right.$ $\% \cdot \min , n=4)$, respectively $(P<0.05)$. In rats whose catecholaminergic neurons were denervated with i.c.v. 6OHDA, basal levels of 5-HT and 5-HIAA were 27.7 \pm 7.9 fmol $/ 40 \mu \mathrm{l}$ and $2.8 \pm 0.5 \mathrm{pmol} / 40 \mu \mathrm{l}$, respectively. These values were not altered as compared with catecholaminergic neuron intact rats. As an index of lesion efficacy, the tissue content of NE and 5-HT was measured; the $\mathrm{NE}$ and 5-HT levels in 6-OHDA-treated animals were $16.7 \pm 2.9$ and $252 \pm 37.7 \mathrm{ng} / \mathrm{g}$ wet weight, respectively. These figures represent $5.70 \%(n=5, P<0.01)$ and $125 \%$ $(n=5$, n.s.) of the levels detected in the non-lesioned animals. The $\mathrm{K}^{+}$-evoked 5-HT release was also significantly attenuated by clonidine $\left(10^{-5} \mathrm{M}\right)$ in 6-OHDA-lesioned rats. The AUC was $11.6 \pm 2.37\left(\times 10^{3} \% \cdot \min , n=5\right)$. The 5-HIAA output was not affected by potassium stimulation in either nerve-intact rats or catecholaminergically denervated rats.

Through the use of microdialysis, the present experiment demonstrated that clonidine inhibits depolarization-induced endogenous 5-HT release in the hippocampus of freely moving rats. The release of 5-HT from different rat brain preparations in vitro is inhibited by 


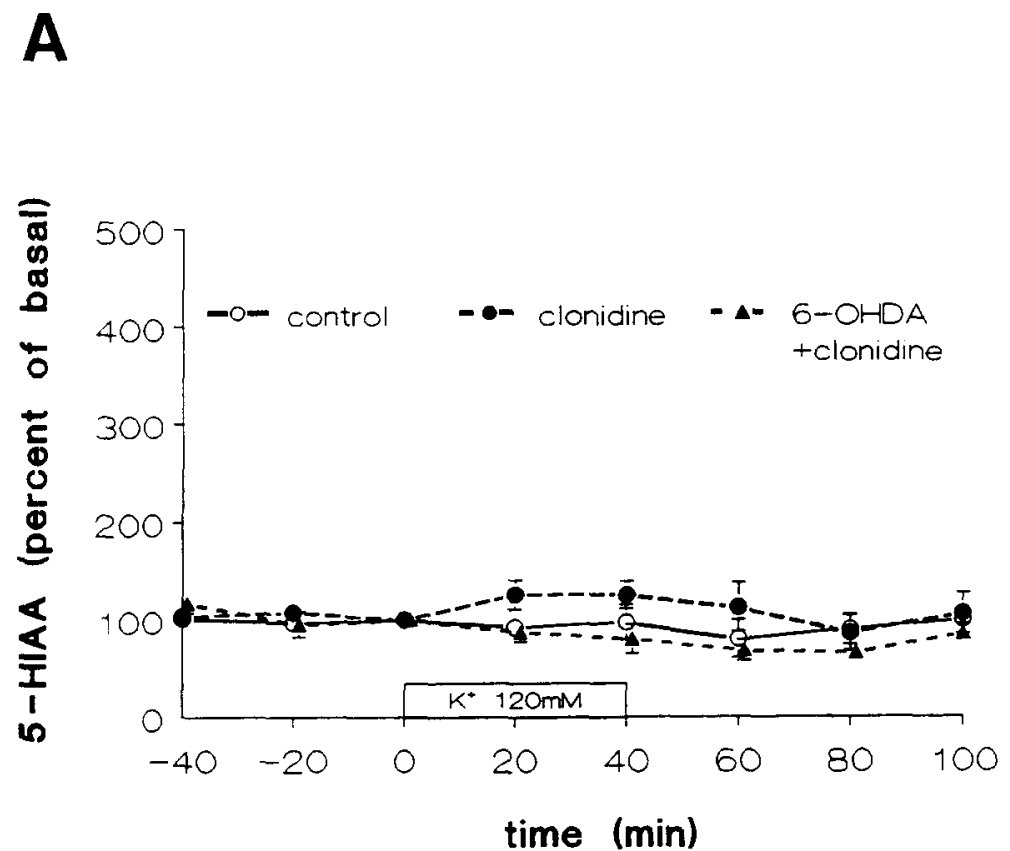

B

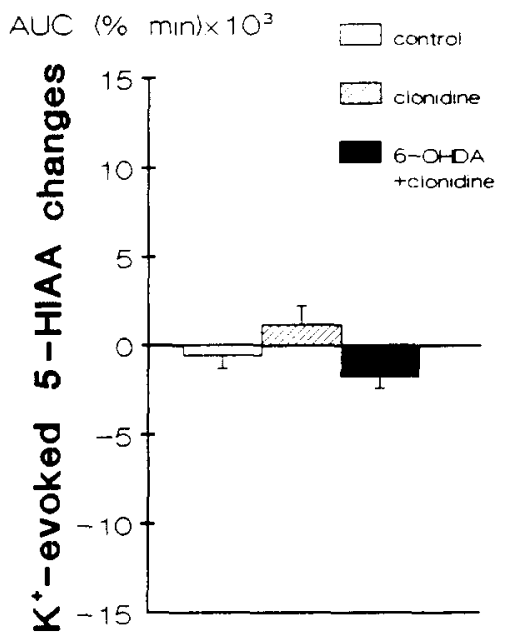

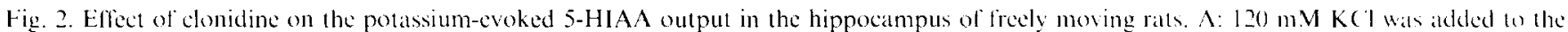
perfusion solution for $40 \mathrm{~min}$ with $(\bullet, n=4)$ or without $(, n=5)$ clonidine $\left(10^{5} \mathrm{M}\right)$ in intiat rats. $\Delta$ represents 6 - $(0 H D)$ - lesioned rats with clonidine $\left(10^{\circ} \mathrm{M}, n-5\right)$. Fach point represents the mean $\mathrm{S}$ S. E.M. B: areas under the curves (AUC) were calculated and each column represents the nean +

S.E.M.

the activation of $\alpha_{2}$-adrenoceptors located on the 5-HT nerve terminals $[1,2,8,11]$. The present data are in agreement with those of previous in vitro experiments and also support the possibility of local modulation of transmitter release from the serotonergic neurons by noradrenergic neurons.

The present investigation revealed that $\mathrm{K}(120 \mathrm{mM})$ induced an increase in the 5-HT concentration of the perfusate from the hippocampus of freely moving rats. Under these conditions, changes in stimulated 5-HT overflow probably reflect changes in endogenous $5-\mathrm{HT}$ release from the serotonergic neurons of the hippocampus. It has previously been shown with a microdialysis technique that the steady-state level of 5-HT can be elevated by the addition of depolarizing concentrations of $\mathrm{K}(120 \mathrm{mM} .60 \mathrm{~min})$ to the perfusion medium in the hypothalamus of the rat [5]. In the present study, although a similar basal level of 5-HT was obtained, the same concentrations provoked an increase in extracellular 5-HT in the intact rat hippocampus, which was approximately twice higher than the increase reported by Matos et al. [5] in the rat hypothalamus. This discrepancy may simply be due to the difference in brain areas. In contrast to 5-HT, the output of 5-HIAA in the intact animals was not affected by the depolarization of 120 $\mathrm{mM} \mathrm{KCl}$. The reason why the 5-HIAA levels are not altered may be that the extracellular space 5-HIAA levels primarily reflect the intraneuronal metabolism, and only to a minor degree the metabolism of 5 -HT released from the nerve terminals. The proposal that 5-HIAA reflects the intraneuronal metabolism of 5-HT and not the release of 5-HT was made by Grahame-Smith [3].

Furthermore, the present experiment using rats whose catecholaminergic neurons are denervated by 6-OHDA shows that 5-HT release is still inhibited by addition of clonidine to the perfusion solution. This suggests that $\alpha_{2}$-adrenoceptor-mediated 5-HT-releatse modulation might be elicited via a 'heteroreceptor' on the serotonergic nerve terminals. Thus the possibility that the inhibition of 5-HT release by clonidine is an indirect action. e.g., mediated by short interneurons, can be excluded. However, we did not observe up-regulation response. i.e.. enhancement of $\alpha$-adrenoceptor function.

In summary, potassium-evoked 5-HT release from the hippocampus of freely moving rats was inhibited by clonidine $\left(10^{5} \mathrm{M}\right)$ added to the perfusion solution in both intact and 6-OHDA-lesioned rats. Taken logether, these results suggest that the inhibitory effect of clonidine on 5-HT release from the hippocampus might reffect the activation of $\alpha_{2}$-adrenoceptors which are located on the serotonergic nerve terminals and that this mechanism might also play a physiological role in the hippocampus.

I Frankhuyzen. A.l. and Mulder. A.H.. Noradrenaline inhibits depolarization-induced ${ }^{3} \mathrm{H}$-serotonin release trom slices of rat hippocampus. Eur. J. Pharmacol., 63 (1980) 179 182. 
2 Göthert. M. and Huth, H.. Alpha-adrenoceptor-medialed moduliation of 5-hydroxytryptamine release from rat brain cortex slices. Naunyn-Schmiedeberg's Arch. Pharmacol. 31:19811) 2126.

3 Grahame-Smith. D.G.. Studics in vivo on the relationship betueen brain tryptophan, brain 5-HT synthesis and hyperatetivity in rats veated with a monoamine oxidase inhibitor and a tryplophan, I. Neurochem. $18(1971) 10531066$

4 Loy. R.. Koziell. D.A. Lindsey, J.D. and Moore. Y. Noradrewergie innervation of the adule rat hippocampal formation. I. Comp. Neurol. $189(1980) 699710$

5 Matos. F.F., Rollema, H. and Basbaum. A.I. Characlerization of monoamine release in the lateral hypothalamus of awake freely moving rats using in vivo microdialysis. Brain Res. 528 (1990) 39 . 47.

6 Matsumoto. M., Effect of ketanserin on adrenal sympathetic nerve activity in rats, Jpn. J. Pharmacol. 48 (1988) 57 66.

7 Matsumoto, M.. Togashi, H.. Yoshioka. M.. Hirokami, M., Morii.
K. and Saito, H. Simultancous high-performance liquad chromats. graphic determination of norepinephrine. serotonin, acetylcholino and their melabolites in the cerebrospinal flud of amaesthetized normotensive rats, J. Chromatogr.. $526(1990) 110$

8 Matura. G., Gemignani. A. and Rateri. M. Doratrenaline inhibits centrall serotonin relase through alpha2-adrenoceptors located on serotonergic nerve terminals. Naunyn-Schmiedeberg's Arch Pharmacol. 334 (1982) 323. 326.

9 Moore, R.Y. and Halaris, A.E. Hippocampal innervation by serotonin neurons of the midbrain raphe in the rat. I. Comp. Neurd. $164(1975) 171-184$.

10 Paxinos, S. and Watson, C.. The Rat Brain in Stereotaxic Co-ordinates, Academic Press. New York. 1986.

1) Starke, K.H. and Montel, H.. Involvement of alpha-receptors in clonidine-induced inhibition of transmitter release from central monoamine neurons, Neuropharmacology. 12 (1973) 1073-1080. 